\title{
IMPLEMENTING COMMON DATA ENVIRONMENTS IN ARCHITECTURAL TECHNOLOGY STUDIES
}

\author{
JOAO LUIS PEREIRA DE SA \& PABLO HECTOR GONZALEZ ALFARO \\ Architectural Technology and Construction Management, Copenhagen School of Design \& Technology, Denmark
}

\section{ABSTRACT}

The Construction Industry's digitalisation is an iterative and ongoing process where digital tools have been primarily focused on the design and modelling and lacking traction in the adjacent stages. Communication methodologies between parties are not evolving at the same rate compared with digitalisation production. Similarly, educational institutions lack the resources to facilitate the students' growth associated with the BIM process. Different commercial entities have been tackling the issue for some time, producing tools that significantly reduce this effect. Implementing a CDE (Common Data Environment) in a pedagogical environment can improve multidisciplinary feedback across lecturers teaching different building specialities. Using digital solutions with an intuitive human interface reduces the distance between students and teachers. A CDE tool such as Dalux ${ }^{\circledR}$ provides a platform aimed for the AEC industry with an amplitude of instruments that serve the building's whole information cycle. The Copenhagen School of Architectural Technology and Construction Management has consistently been implementing in their programs the most recent BIM solutions to provide new graduates with competences to cope with industry challenges. In doing so, innovative applications of didactics strategies have been successfully applied in the light of favourable results. Students need a comprehensive understanding and application of communication flows when solving their school assignments from an industry practice perspective. In 2020, the school decided to implement Dalux in the program as a pilot project to analyse the feasibility of using the software on a major scale with promising results. This paper presents the Dalux implementation at the school, exploring the didactic and professional approach based on factual data from case studies and learning outcomes during the period of investigation.

Keywords: AEC, CDE, Dalux, documentation, digitalisation, communication.

\section{INTRODUCTION}

The application of digital solutions to enhance the Danish building industry productivity has been performed for more than 15 years, fostered mainly by the public sector. However, in the last years, the private sector understood the benefits of using BIM and, by synergy, become more integrated into the development of the industry. The ICT (Information and Communication Technology) regulations that are in force in public projects now became the standards to coordinate BIM performances. Within its processes, fluid communication amongst the different actors involved in a building project has become the most discussed topic to be the next step to develop building projects in a more efficient fashion. All the tools are at the disposal of the building industry. Still, it misses the capability of coordination and collaboration, especially when it comes to involving small companies due to the lack of BIM maturity.

Clients in Denmark have an increased interest in using sophisticated digital platforms for improving coordination and a better understanding of levels of collaborations. Therefore, it is vital to find flexible systems that can offer solutions and support the challenges that the interactions amongst project participant have in a project. Amassing a design and construction team can be done differently where the success of a project depends on the selected system of BIM and communication platform [1]. The main domains that drive clients to decide the right solution are based on a product that can offer optimal coordination, a quick overview of the project's status, and digital applications that 
can ensure quality. The industry is awaiting the next step in CDE applications - yet to come. On the other hand, educational institutions in Denmark contribute with different resources to accompany the rapid pace that the development of CDE technologies is showing recently.

\section{APPLICATION OF CDE IN THE INDUSTRY AND PERSPECTIVE FOR EDUCATION}

Better productivity rates in the industry require a strong linkage between cooperation and the technology that makes it possible. One tool used for planning digital communication is a BIM execution plan that sets the information level and the type of data traded amongst the project participants and designates a BIM manager who leads the team. To succeed in a project, it is key to plan the team's coordination at upfront stages using BIM to connect design, budget, schedule, planning, and facility management. Software vendors consider these basic requirements as opportunities to expand and increase their share in a tough and competitive market. The primary strategy consists of providing clients with flexible platforms and streamlining all project participants' interaction through a standard digital structure. This leads to a market that offered multiple software solutions with different capability ranges. Today some communication platforms cover most of the stages in the life cycle of a building, and its usage in Denmark has become widespread.

\subsection{Levels of collaboration in Denmark}

When having a look at the level of complexity of BIM applied for different building projects, the range varies from 2D BIM (drawings), 3D BIM (virtual elements with nested data), 4D BIM (time operation), 5D BIM (cost performance), 6D BIM (sustainability approach) and 7D BIM (operation and facility management) [2]. The definition of the boundary conditions where the complexity of BIM and the levels of maturity interact in the context of a specific project is not an easy task. In this regard, through several initiatives, the public and private sectors have understood that coordination and collaboration via clear definitions of roles are crucial for the sustainable growth of the construction activity. Clients are the key stakeholders in a procurement organisation that thrusts the level of collaboration in a team. They can exert power over cooperation from the early stages in the design - this is especially critical for Integrated Procurement Delivery organisations and set the degree of integration and expectations from all the team members.

In Europe, countries that understand BIM as the present and the future in the building industry have developed actions and means to realise a feasible approach of digital construction: public procurement, standardisation; research and development; and education [2]. In Denmark, the Executive Order number 118 of 2013 and Executive Order 119 of 2013 constitute the legal frame that regulates projects subject to mandatory ICT agreements in the public sector and projects in social housing. The Danish Association of Consulting Engineers and the Danish Association of Architectural Firms has developed the "Description of services for building and landscaping 2018", which outlines roles, divisions of services and responsibilities for all the professionals involved in building projects through works stages from brief to handover. The document includes a dedicated section that addresses ICT matters and gives general guidelines about digital communication and the establishment of a communication platform. The non-profit organisation MOLIO provides the building industry with standards and instructions that connect regulations and practice to coordinate ICT. Besides this, one of the most critical strategies that the Danish Government has put in place the last 15 years has been fostering research and development 
related to BIM via educational institutions and public offices to increase the expansion and application of BIM at all levels to obtain a shared digital language regardless the discipline.

In the light of the increased demand for solutions to face the communication and coordination challenges in the industry, different software vendors have developed products that cover, to a lesser or a greater extent, the practical demands that digital collaboration requires. The reality is that there is no one software and communication platform that can provide solutions for all types of projects. Nevertheless, there is a need to find "one single ecosystem" that can combine applications supplied by different software [3]. Digitalisation and efficient applications of CDE have become critical competitive factors in the industry due to the increased chances of success offered to all project's participants. Clients in Denmark are investing in digitalisation and CDE yet lagging compared to other sectors.

\subsection{How a CDE facilitates collaboration in building projects}

As per ISO 19650, a Common Data Environment CDE is an agreed Source of information for any given project asset [4]. This data aggregation enables different parties to participate and contribute to the project in all its steps through its life cycle. CDE can be simple digital storage like Dropbox or OneDrive - what defines its scope and form is the ICT agreement. Several other forms of CDE are present in the construction market in Denmark, some nondedicated to AEC and others adapted and bound to the construction industry as Byggweb and Dalux as digital storage means for building projects documentation. CDE integration with BIM tools such as Revit, Navisworks and ArchiCAD is of the utmost importance since it is in these software where all the geometric and non-geometric data gets created and updated.

Platforms based on cloud storage enables all members to access the latest information and cooperate in a manner where all reach the same documents, improving data handling and reducing confusion in newer versions or duplicates. When a file is updated, the previous versions are stored in a straightforward interface with a shared directory. One of the most capable solutions is the possibility of seeing the newest version even with a printed document; for this Dalux uses QR codes printed in the documents, giving certainty on site and the potential to revise the alterations that occurred concerning the version printed. This tool being dedicated to the construction sector can have a file structure following national directives, and in the case of Dalux, can be adapted to any company standards. In the Danish context, Dalux defaults to the file structure Molio A104, a standard widely adopted file storage and naming in the country.

\subsection{Communication platforms in building projects enabling non-BIM to BIM}

The pursuit of efficient digital communication and establishing a collaboration platform try to solve cross-disciplinary coordination amongst the project participants. Effective interaction ensures the proper distribution of data in a structured manner throughout project design, construction and operation. Proper digital communication allows systematic registration processes of exchanged data and determines the responsibility and quantity of information delivered by the members of a project team. To achieve all these goals, the client has to decide who will set up the communication platform and (through respective consultancy services) delimit the extent of the system's performance. The management of metadata, versions and revisions; protocols for the definition of a folder structure, application of systematic processes via templates, and access to data through the usage of 
mobile devices, are critical factors to be considered when defining the type of project web to be used in a building enterprise [5].

The most prominent suppliers of complete digital project platforms solutions in the Danish market are Dalux, RIB Software and Ajour System - all of them based on cloud technology. All these products serve the same purpose in attracting public and private clients by offering solutions that are becoming more flexible due to high competition and continuous development resulted in an output of adaptation as the market evolves. The file management platform, and its means for ensuring a safe and sturdy hosting environment, are standard key parameters displayed by these products. All the data generated along with the project phases (from tender until handover and operation) can be managed across the different disciplines allowing quick access to information and providing features for 3D BIM visualisations. Previous definitions of hierarchy levels within the BIM project team, folder structures, communication workflows, and open industry standards as IFC permit all the participants included in the communication platform to use digital production. Since proper collaboration is promoted at early stages as the key to success, the available software focuses on coordinating design outcomes where the input that stems from various disciplines can be organised internally and externally through the generation of federated BIM models.

\subsection{Usage of communication platforms in education: A fragmentary approach}

As in other academic institutions, The Copenhagen School of Architectural Technology and Construction Management, hereafter ATCO school, uses Learning Management Systems (LMS) such as Blackboard, Docebo and others. The ATCO school uses the tool called Fronter. The platform is adequate. It can create and upload several class resources, in different types of file extensions, with varying types of access according to the courses the students should have to gain access to. The management of this tool is done before the semester starts. All students are given suitable access to their semester's courses, and the teachers are also incorporated in the respective semester disciplines. Fronter is a resource aimed for broad usage in education topics. It has been effective and proven to be a good communication tool. Still, with the intensification of digital documentation resulting from the BIM process, the assessment of the teaching staff to all the new digital submissions has been challenging. The tool relies on a fragmentary approach where different lecturers have access to further deliveries from the students.

Since multiple disciplines are aggregated in the BIM model, the documentation produced needs to be uploaded several times for the different assessments by the staff. In a final stage, the students have to assemble all comments and revise their designs in the 3D model. This workflow is problematic. Not every time the different teachers have access to the same version, and some comments can be redundant as intercommunication between the staff is not possible via this LMS. This problem is not new, the AEC industry has been struggling with it, and CDE tools have evolved to the specific industry needs. Software as Dalux has been adapting its features to the construction needs and its rapid digitalisation. It is not rare that the ATCO school students, after their internship period, refer that this tool has been in use in architectural practices and engineering offices with success.

\subsection{Implementation of Dalux at ATCO school}

In Denmark, BIM implementation and regulative parties have influenced the way the industry is developing. Educational institutions must work hand in hand to go along with 
such developments providing the industry with professionals that understand processes and work as a team. Teaching BIM is an immense challenge that requires the proper framework to align different approaches and understandings of BIM. Curriculums have to be adaptive to allow an appropriate integration at all levels of BIM complexity when teaching. Therefore, pedagogics through well-designed learning methods are essential to bringing an institution the tools for solving problems in an industry that is technical and based on practice. The ATCO school has been implementing BIM content in its curriculum for more than ten years. Great success has been achieved due to continuous improvement of the didactical and pedagogical approach. Graduates obtain multiple competences to cope with a wide range of tasks and situations presented in the professional practice and are given the capacity to produce new knowledge and innovation and transfer these fundamental factors of development to the industry. The teaching method and its BIM incorporation provide an adequate environment for students to be accountable for their learning process by setting activities to promote self-engagement and motivation.

At ATCO school, the teaching is didactically founded on Project Based Learning (PBL). Groups of students withstand a real-life project and correlate a feasible solution with their available resources in order to learn [6]. There is a set of instructions provided by the teachers (facilitators) where relevant problems related to a building project are presented to start the cycle that ignites the learning process. Through cross-disciplinary consultation and feedback, the students will connect the different learning outcomes for the topics included in the semester, delivering at the end of the course a completely designed project including primary BIM assignments. The proposed technology to make all these possible is based on assuming that communication and collaboration through digital technologies are crucial if the school seeks to depict real-life scenarios. Although the current LMS platform functions appropriately in terms of being an efficient resource in the learning process, there is a question of whether it has the flexibility to be used as a tool for simulating a real-life situation as a communication platform amongst stakeholders. In 2019 the ATCO school initiated a collaboration with Dalux, which lead to some isolated pilot projects by some lecturers. In the light of preliminary results, the staff involved in these projects decided to unify outcomes, reason and conclude. Afterwards, the team proceeds with an extensive field test and research to analyse the implementation of Dalux as a communication platform on a large scale in the program.

\subsubsection{Brief description of Dalux}

Dalux provides a unique ecosystem where the students can prepare their deliverables, simulate work stages and communicate with peers and lecturers. The information in the platform arrives and flows in a variety of different formats, such as drawings, documents, cost calculations, schedules and BIM models. The system includes a series of modules: Dalux Tender, Box, Field and FM, where the progression and evolution of the project can be easily tracked. Additionally, the opportunity of setting communication channels through the creation of workflows and levels of hierarchy allows the students to interact together and have access to valuable 3D views and reports with attached pictures that can be combined with 2D drawings. Dalux Tender allows to simulate any kind of competition, sets levels of communications (with or without restrictions), allows replying to questions from the competitors, and submitting the proposals. Dalux Box provides file management and organisation that can eventually be fed by information already existing in Dalux Tender. Dalux Field supports processes happening on the construction site. Together with the Dalux BIM Viewer for AR (Augmented Reality), mobile devices combine and compare physical construction with BIM models. Finally, Dalux FM is a BIM and cloud-based Computerised 
Maintenance Management System (CMMS) to assist complete overview of all the building assets and manage work orders. These modules have been successfully tested and implemented at the ATCO school through different semesters, adapting learning outcomes to levels of complexity as progression goes on.

\subsubsection{Dalux at KEA workshop}

To show the software's capabilities, the implementation team organised an online workshop in early 2021. The lecturers and Ole Jetmundsen - (Dalux consultant) introduced several software capabilities to teachers and students at the KEA buildings department. In total, 64 attendees have attended, 57 students and seven lecturers, representing a good ratio of the KEA's academic community.

The workshop covered the basics of the software, explaining the primary User Interface (UI), creating a project in Dalux following the Molio A104 file structure standards, and adding the different contributors with the correct access to the information folders. During the workshop, a demonstration showed how to export an IFC model to the CDE via the Dalux Revit plugin - uploading of Revit sheets to the platform also possible (Fig. 1).

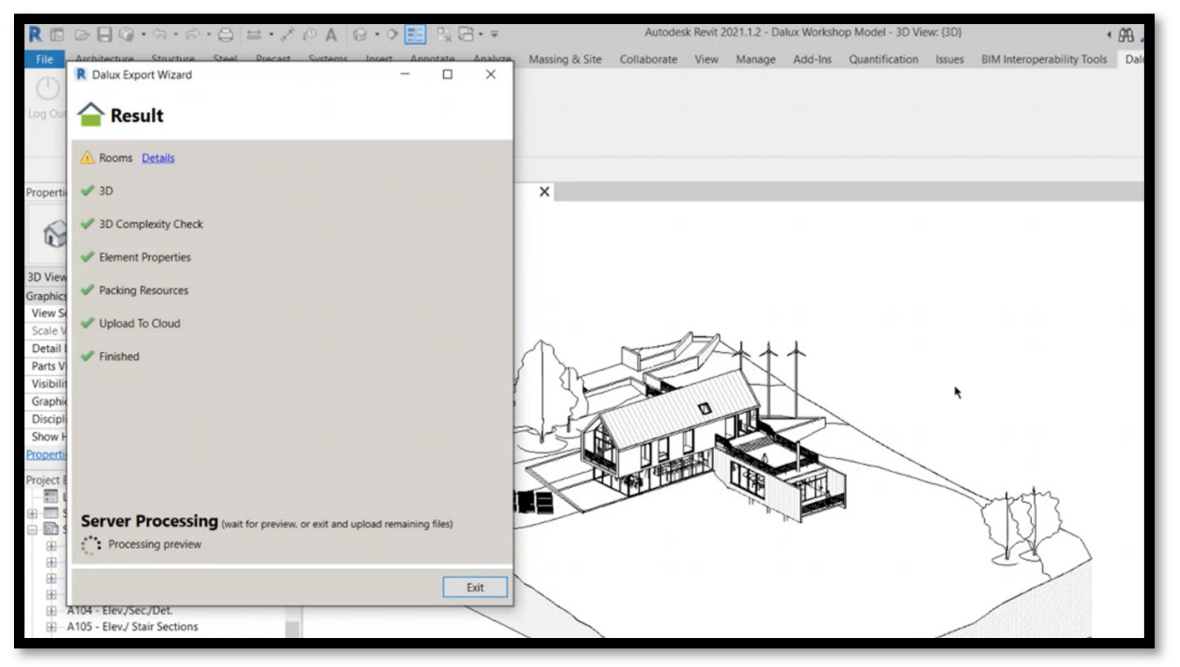

Figure 1: Exporting data from Revit using Dalux plugin.

When uploading from Revit, the sheets are automatically aligned with the correct levels and merged with the 3D. It was also shown a Dalux view mode, where both 2D and 3D are aligned - this is a solid way to inspect any discrepancies between the visual project data (Fig. 2). The software 3D visualisation is robust, allowing the user to navigate/walk virtually in the project. This feature is a keystone for success in the implementation of Dalux - it will enable non-proficient BIM staff to evaluate and create comments that are available for the students to correct afterwards.

Once the issues/comments have been created in the Dalux web interface, the students can revise them directly in Revit. The plugin includes a comment browser that attaches to the right of the drawing area in Revit (Fig. 4). This ability to review comments in Revit UI is essential, as the comments are directly shown and revised in the students' core tool. 


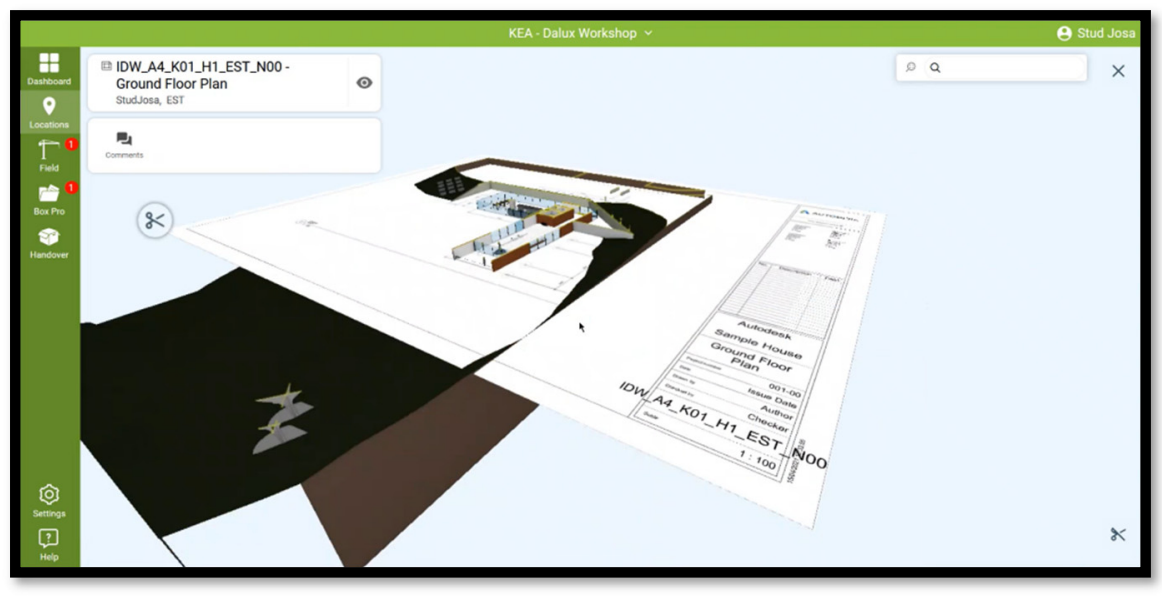

Figure 2: Merge 2D with 3D.

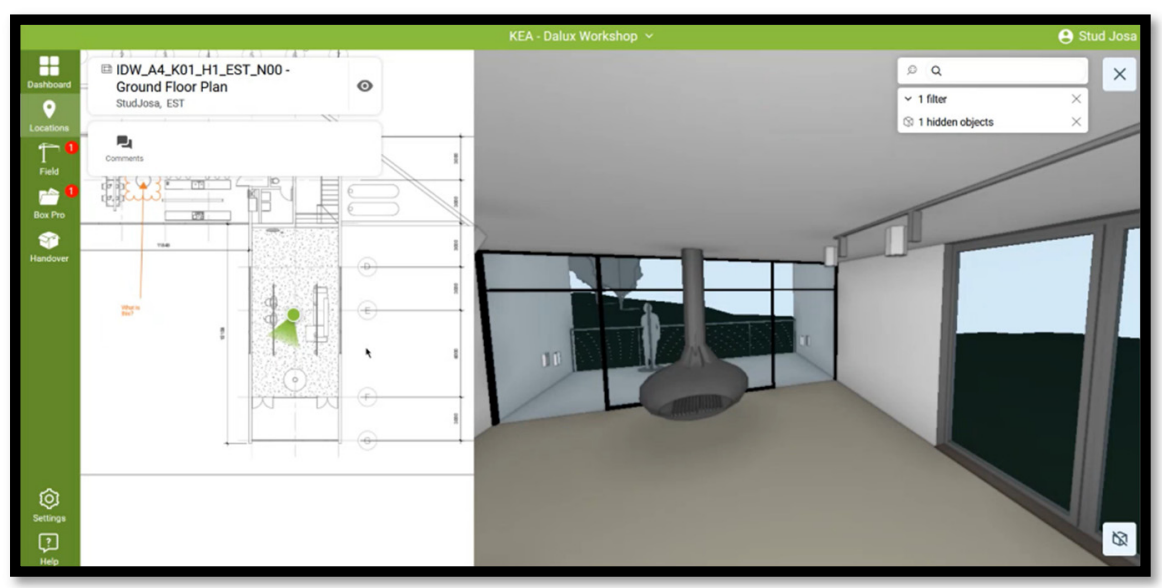

Figure 3: 3D navigation in Dalux.

\subsubsection{Advanced BIM for digital tender: Elective course (third semester)}

The elective course aims to work with digital tender in construction projects using ICT technologies. The program's focus is on the potential improvements that BIM offers to the construction sector by using advanced digital technologies, optimising the tender phase and the core deliverables of contractors in the construction phase. It is expected that students will acquire knowledge, skills, and competences about using ICT in digital construction projects delivered in different procurement forms. There is a strong focus on applying ICT standards, specifications and advanced digital tools for performing consistency and collision control in the 3D models, handling digital tender and digital platforms. The course includes applying 5D BIM processes for preparing model-based quantity take-off, bid 


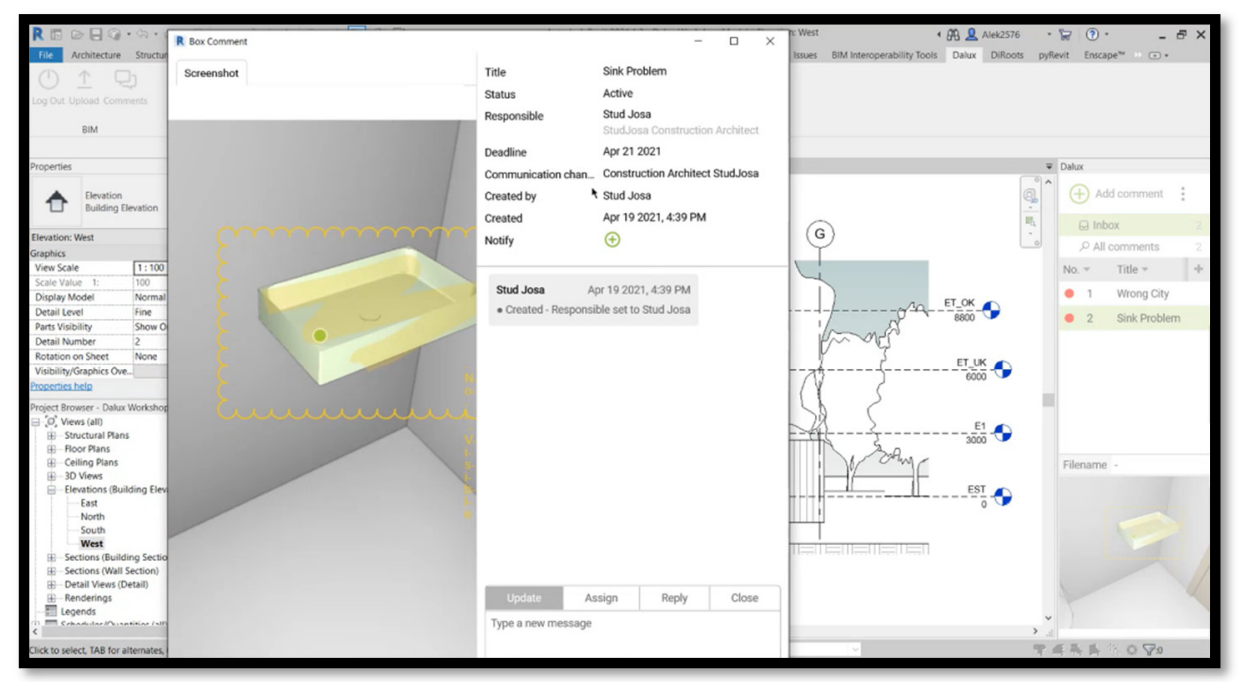

Figure 4: Issue/comment review in Revit.

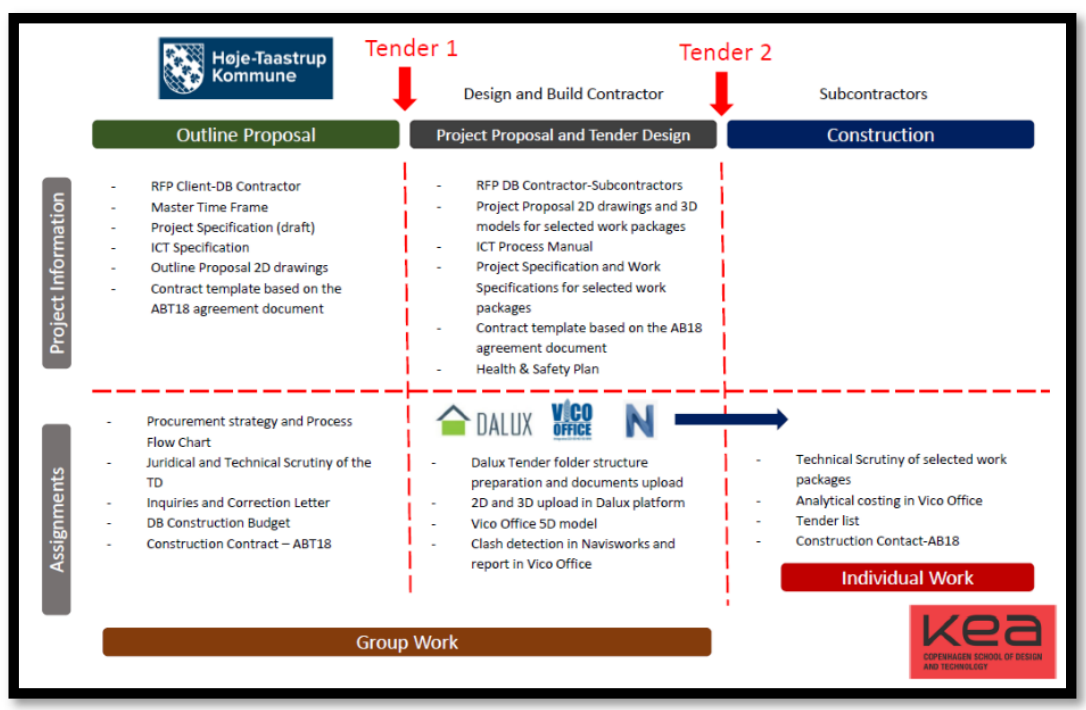

Figure 5: Project information: Procurement forms - Main assignments.

estimates and bids submission, and 4D BIM process simulation for selected phases of the construction process. The students are confronted with a series of exercises to obtain indepth skills in planning and managing digital tendering processes, including preparation of a detailed tender phase schedule, management of documentation, specification of participating actors, services and interfaces, as well as the organisation and contracting related aspects. The students will work with a tender documentation package that 
corresponds to a real-life project - a new public administration building category. The released tender documentation package (handed out in a digital form) will be the core material used for the primary assignment in the course. Students scrutinise the tender documentation and prepare selected deliverables of the Tender Managers and Contractors performing in the Tender and Contract stage. Students upload the tender document in Dalux, which is the platform used as a communication tool for tenderers. Additionally, the students will use Navisworks and Vico Office BIM tools as a part of the scrutiny and costing assignments - all the outputs are uploaded in Dalux.

The course presents several challenges to the students since the project, during design stages, involves two tender phases where dynamics between assignments can be complex. The groups are given two tender packages that have to be scrutinised. Once the review is finished, the groups transfer questions to enquiry letters and perform cost calculations, schedules and contracts. Tender packages are including architectural, structural and ventilation systems BIM models. One relevant activity included in the scrutiny process is to use the BIM models as the primary resources to prepare inquiry lists and correction letters. Vico Office is the software that the students use for costing (5D) and scheduling (4D) purposes. Vico Office itself included several modules where the project information can be stored, processed and updated. One of these modules consists of a report engine that allows communication amongst the different disciplines. The students perform a clash detection control by using Navisworks, obtaining a report and exporting the results to the Vico Office module called Managed Issues. When the scrutiny of documents and BIM models has been finished, the groups will upload the original tender packages in Dalux Box for simulating a tender stage. To do that, the groups have to create a project, set rights and hierarchies and establish communication workflows where the client will communicate with bidders to reply to questions, receive proposals, negotiate and sign a contract. The course ends with an exam, where the students have to show all their outcomes in an explanatory presentation that includes opening Dalux Box performing demonstrations and display results.

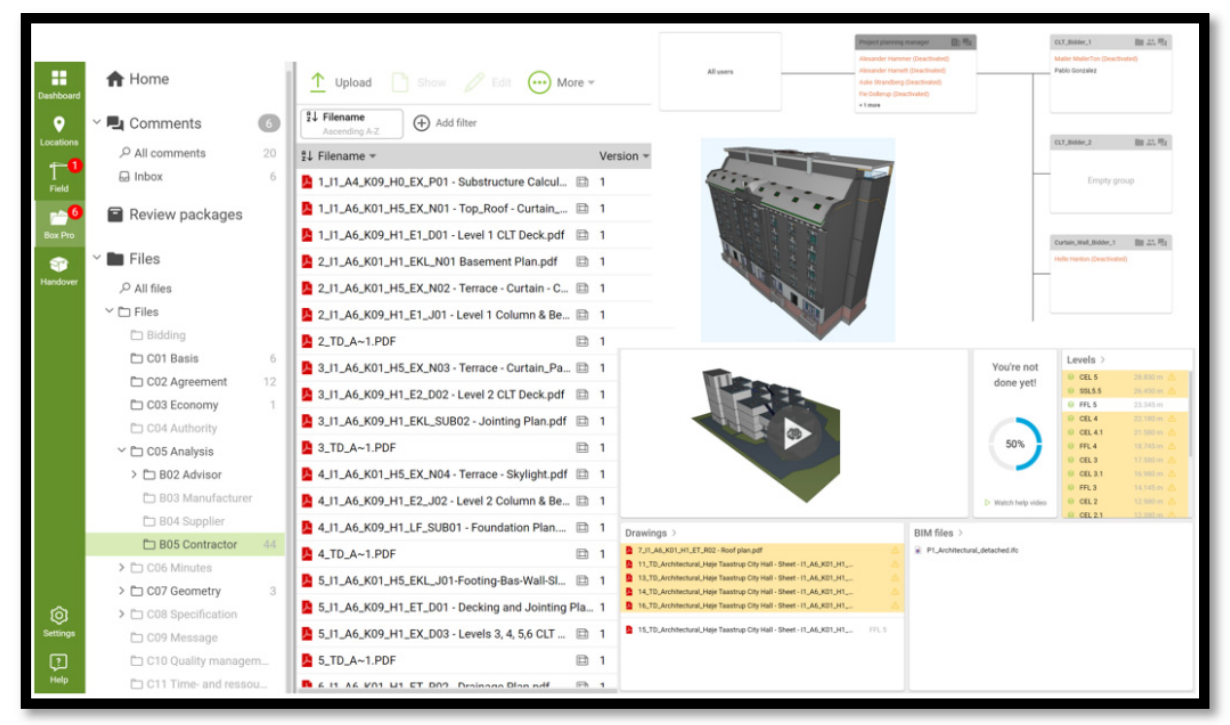

Figure 6: Dalux box: Digital tender. 


\subsubsection{Construction stage: Elective course (fifth semester)}

The course includes selected construction management deliverables of the Client, Contractors, Design Professionals, Fabricators, Suppliers and Agencies performing in the Construction Stage. Students should strengthen their knowledge within Planning and Construction Management and develop specific Construction Management knowledge and skills about the process and core deliverables of the Construction Stage. One of the topics discussed during the course is the Handover Protocol with a general approach and afterwards more focused on the Danish scope with a specific view taking as a reference the rules set by the "General conditions for building and construction works and supplies (AB18 - ABT18)". The handover stage is an essential process in a building project. Defects associated with the performance of different trades relate to this stage. The protocols used to register and remediate imperfections constitute crucial processes that affect the productivity and the quality of the building. Additionally, the handover (with its milestones) is a legitimate critical period perfectly regulated by the agreed documents $\mathrm{AB} 18$ and ABT18. The parties involved in a project may conduct a pre-inspection meeting before the formal handover event, where there is a registration and discussion about the quality of the product that, in most cases, will lead (amongst others) to a request for rectification of any defect found during the actual inspection. Since the registration of defects can be a complicated process, it is essential to set the strategies, workflows and a platform where client, contractors and subcontractors will communicate [7]. So far, in the scope, the preparation of a defect list has been based on forms to be filled out manually and to a good extend by using cloud services that allow photo recording by using mobile devices. However, these methods lack proper communication channels amongst project participants and the inclusion of an engine that permits comparisons between BIM models and reality. Dalux Field is one solution to this requirement. It poses all the tools to combine project information, set communication workflows, and digital documents with excellent usage flexibility. A 3D model can be correlated with the physical completed building providing capabilities of recording defects or sending requests - all these indispensable applications to improve efficiency and quality.

In this elective course, the students work on a refurbishment project. All the design and planning information related to the project used for the exercises are the outcome of the students' performance during their mandatory course. The planning subjects included in the program are the definition of the project procurement connected with the site organisation, detailed demolition plan, construction technology analysis, health and safety plan, 5D and 4D performances, payment plan, and a defect list disaggregating trades by using Dalux Field. For the performance of the defect list, the groups will create a project in Dalux and add as many work divisions as the refurbishment project will include. The first step is setting the 3D model in the Locations and combine sections by levels with 2D drawings eventually, the students will include views and elevations as a part of the technical design. Back in Dalux Field, the students will create work packages, and they will align the performance of a defect list with some of the trades included in the project - most of the time carpentry works, masonry works, steelworks and painting. To set a work package, the students have to create workflows where the communication channels amongst the project participants have to be defined.

Once the work packages are ready, the students can start creating tasks that for the performance of the defect list are called "issues". Other tasks that can be added are Deviation (DV), Quality Assurance (QA), Registration (REG) and Test (TEST). Regardless of the type of preset task that Dalux Field includes, there is always the possibility of 


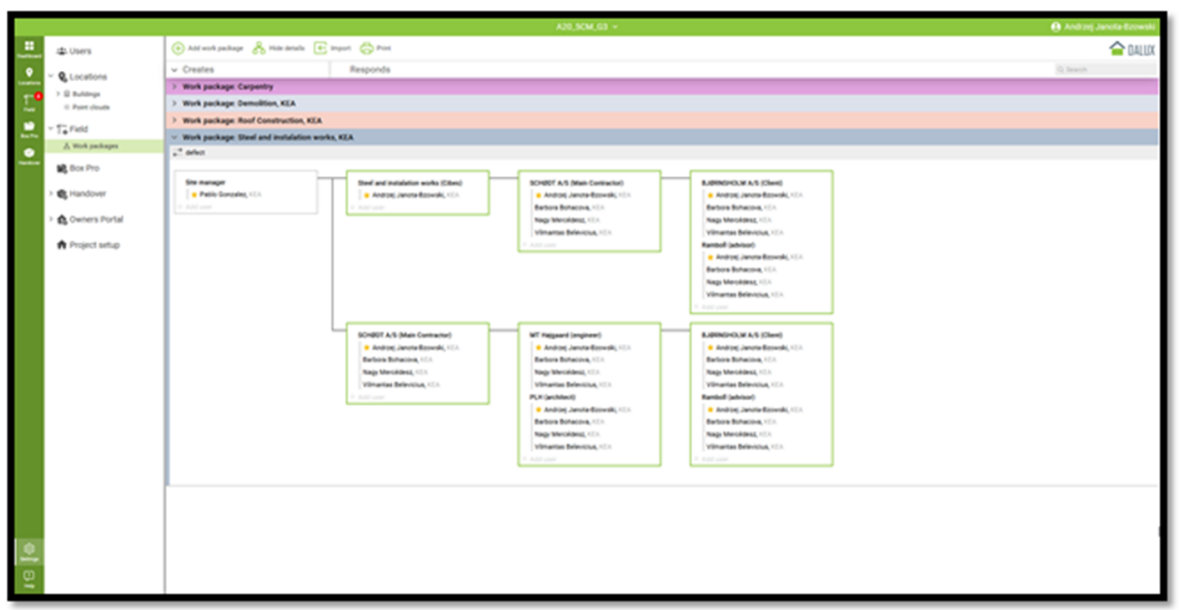

Figure 7: Dalux field: Work packages and communication channels.

creating other types of tasks, such as health and safety inspections monitoring tools. The students have to research and find the most common defects in refurbishment projects and find pictures that show those issues. Once the research is finished, the students can create issues in Dalux Field, assign a responsible (connected to the work packages) and connect the $3 \mathrm{D}$ model with a $2 \mathrm{D}$ drawing pointing exactly where the defect is located in the building and attach a picture. At the end of the exercise, there will be a list of defects in Dalux Field, with the possibility of tracking remediations and navigating the $3 \mathrm{D}$ model at the same time.

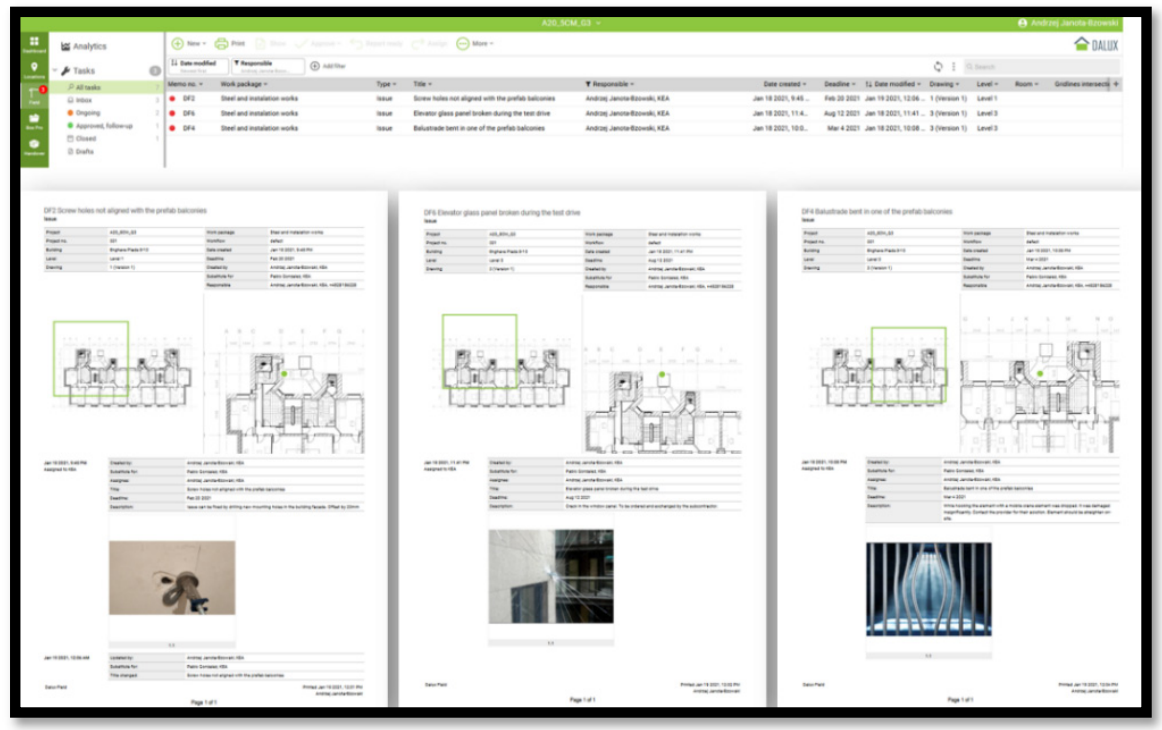

Figure 8: Dalux field: Issues, defect list and location. 


\section{OBSERVATIONS}

The implementation of Dalux in the different courses resulted in a series of analysed outcomes from the pedagogical point of view that were extrapolated to a broader and more integrative scenario. The defined learning outcomes specified in the lecture plans were confronted with the students' presentations of results and complemented with surveys. The students managed to use all the modules included in Dalux and showed an understanding of the software as a versatile tool for data management. While going through the different exercises, there was a clear connection between how information has to be arranged and communicated and technical requirements and guidelines given by the Danish standards.

\subsection{Outcomes}

Collaboration via Dalux helped the groups' members work together and innovate in workflows and coordination. The usage of Dalux facilitates motivation, profound learning processes and understanding of the different stages involved in the resolution of tasks in building projects. Several disciplines can communicate via BIM models in the same ecosystem by using $\mathrm{CDE}$, where the integration of inputs accomplishes the teachers' expectations.

Students were asked their opinions about having used Dalux, and answers included, "It is a very efficient tool, maximising the use of time and binding together core actors involved in a project also during the construction site. Very easy to understand and work with it and a great platform for communication. Real-life software for creating, assigning and solving problems"; "My experience working with Dalux is extremely positive, from all the new software we worked with at KEA it is the most efficient and I enjoyed working with it creating a real-life situation for preparing, assigning and solving issues. I can see immense potential for using Dalux. Also, I would like to mention that it is already being used at Metroselskabet \& Hovedstadens Letbane where I am doing my internship"; "I would say that advantages are that it is user-friendly, fast with communication and also that you can use it directly on site and send immediate notes to the relevant people and have immediate action after that." In the light of more comments like those shown above, an assessment indicates that the implementation of Dalux was seen as a proficient mean for communicating, learning and working at ATCO school.

The results below demonstrate the significance of introducing a CDE tool at ATCO. The survey on implementing Dalux at ATCO corresponds to the Dalux Workshop, totalling 64 attendees with a fair representation of docents and students. The questions and results are shown below:

- $\quad$ Q1 - In your opinion, KEA BYG should have a CDE platform like Dalux to enhance project communication/evaluation?

- $\quad$ Q2 - In your opinion, a tool like Dalux can improve communication between teachers and students?

- Q3 - Do you think that a tool like Dalux could be used for Exams at KEA BYG?

To notice in Q3 results that the maturity level at ATCO is not yet at a point where either lecturers or students feel comfortable to use the tool for semester examination; only $50 \%$ of the attendees are inclined to use it. On the other hand, to the Q1 and Q2, over 70\% are favourable to the queries, which shows optimism in the work and allowance to further develop the implementation at ATCO. 


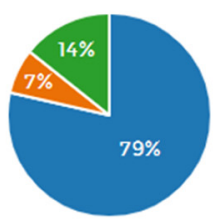

Q1

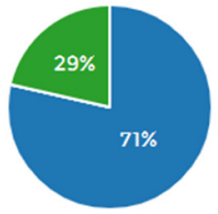

Q2

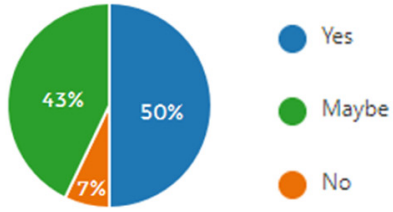

Q3

Figure 9: Survey results - Dalux Workshop in KEA.

\subsection{Industry view}

One of the most important activities that lectures have at ATCO school is networking with the AEC actors in the industry. To keep the education program updated, it is necessary to follow the local and international trends in a business subject to continuous development and change. On the other hand, the teachers have a relevant role as the link between companies and the students when it comes to the internship period. The school has to make sure that interns are ready to cope with a series of tasks based on learning outcomes set by the students themselves - intended to be used in the final dissertation report and bachelor project. Companies in Denmark can see the potentials of interns and graduates when it comes to implementing new technologies and processes and are open to allow them gradually incorporate their ideas and innovations in a cycle that has been accelerating in the last years.

In the autumn of 2020, the Dalux implementation team at ATCO school conducted interviews with several stakeholders in the industry (Dalux users) to obtain input about what could be the most important features and processes to teach in the courses. The AEC actors involved in the interviews stressed the importance of including at upfront stages a clear description of the communication platform in the ICT Specification and Process Manual. The usage of the MOLIO A104 is key to allowing success in setting a proper framework for data management and, in combination with a defined classification system, should allow the performance of disciplines tasks by integration of Dalux modules with special attention to BIM viewer. Setting rights and workflows within the communication platform is a particular competence that the professional should have incorporated for the proper usage of Dalux.

\subsection{Limitations}

The implementation path of a CDE at ATCO is far from concluded since Dalux has several shortcomings. A professional CDE tool is used in an educational context, and the lack of information to fully deploy a CDE might be difficult, as the teaching methodology is built in project-based learning and the semester assignments do not have the necessary scale to see the full potential of a CDE deployment. Competitors such as BIM 360 from Autodesk have the advantage of holding the latest data by default, without the need of uploading data or installing plugins, this Autodesk tool has the advantage of communicating directly with the model hosted in the cloud. The future holds the answers to this study, but having Dalux onboard cooperating with ATCO may have fruition. There is an expectation that the software can be adapted to an educational context allowing for better integration. 


\section{CONCLUSION}

The increase of data associated with the BIM process has led to more precise projects and better simulations; even though the computational power is aligned with that progression, the individual workers have been struggling to handle this volume of information. The ATCO school faces the same issues; lecturers cannot revise the amount of documentation that the students generate with the inclusion of the BIM process, either because it is stored in software that they are not familiar or because the sheer number of documents is just too large. By using a CDE such as Dalux, can help to close the gap created by digitalisation. The software Dalux has a friendly user interface and a strong component in communication between BIM and non-BIM personal. Dalux is a proper tool for AEC educational institutions such as ATCO school, facilitating the linkage between the new generation, highly capable in digital tools and the senior experts that otherwise struggle in helping the students.

The introduction of a CDE in an educational context also increases its adoption by the industry, accelerating digitalisation in companies, moving forward with the national and international directives, minimising waste of resources allowing for better projects. The Danish building industry has seen the potential of CDE, and it is now under preparation for a more integrative usage of communication platforms, resulting in an increased interest for graduates with the right competences to do the job and work as a team in a digital environment. Educational institutions are willing to contribute by setting policies in terms of research and development and transferring the knowledge to the students and the industry simultaneously by bilateral collaboration. ICT agreements and the implementation of standards is vital to set the context and the framework that allows students to implements $\mathrm{CDE}$ in their schools' project. At the same time, it shows a tremendous potential to assist lecturers in their teaching by replicating real-life multidisciplinary work scenarios. In the light of the results after the implementation of Dalux in pilot projects at ATCO school, it seems to be evident the advantages that the application of Dalux could bring to educational institutions connected with the building industry. A wholistic cross-disciplinary pedagogical and didactical discussion is underway to decide the suitable methods and approaches at study situations. That will allow all the lecturers to communicate appropriately via CDE amongst peers and with the students and set a new benchmark to contribute to the industry development to increase productivity.

\section{ACKNOWLEDGEMENTS}

The authors would like to thank Mattias Straub and Jan Lambrecht for the vision, enthusiasm and remarkable collaboration in implementing CDE in KEA, James Harty for all the wisdom and guidance, and finally, Claudio Testa for the opportunity and trust.

\section{REFERENCES}

[1] Thomassen, M., BIM and collaboration in the AEC industry. Thesis. Department of Mechanical and Manufacturing Engineering: Aalborg, p. 120, 2011.

[2] European Commission, Building Information Modelling in the EU Construction Sector. European Construction Sector Observatory, p. 22, 2019.

[3] Eastman, C., Teicholz, P., Sacks, R. \& Liston, K., BIM Handbook. A Guide to Building Information Modeling for Owners, Managers, Designers, Engineers, and Contractors. John Wiley \& Sons: New Jersey, p. 506, 2008. 
[4] ISO 19650 Series of International Standards, 19650-1:2018, Organization and digitisation of information about buildings and civil engineering works, including building information modelling (BIM) - Information management using building information modelling - Part1: Concepts and principles, 2018.

[5] Bygningsstyrelsen, Digital kommunikation og etablering af kommunikationsplatform. Bygningsstyrelsen: Copenhagen, 2021. https://bygst.dk/byggeri/ikt/vejledning-til-iktydelser-og-implementering/digital-kommunikation-og-etablering-af-kommunikations platform/. Accessed on: Apr. 2021.

[6] Prince, M.J. \& Felder, R.M., Inductive teaching and learning methods: Definitions, comparisons, and research bases. Journal of Engineering Education, 95(2), pp. 123138, 2006. https://www.researchgate.net/publication/220017716_Inductive_=Teaching _and_Learning_Methods_Definitions_Comparisons_and_Research_Bases.

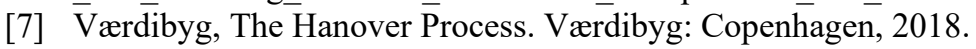

https://vaerdibyg.dk/vejledning/the-handover-process/. Accessed on: 8 May 2021. 